\title{
A study on prevalence of post-partum depression and its associated risk factors
}

\author{
Sujitha Gurram1, Raghuram Macharapu ${ }^{2, *}$, Vijay Kumar M³, Pramod KR Mallepalli", Ravulapati Sateesh Babu ${ }^{5}$ \\ ${ }^{1}$ Senior Resident, ${ }^{2}$ Associate Professor, ${ }^{3}$ Post Graduate, ${ }^{4}$ Professor and HOD, ${ }^{5}$ Professor, Dept. of Psychiatry, Mamata Medical College, \\ Khammam, Telangana, India
}

\section{*Corresponding Author: Raghuram Macharapu}

Email: raghuram.macharapu@gmail.com

\begin{abstract}
Introduction: Postnatal depression (PND) is a common psychiatric disorder and is considered a serious public health issue. It is diagnosed in about $50 \%$ of the women during first year after delivery.

Objective: To assess the prevalence of PND and study the associated risk factors.

Materials and Methods: The study was conducted in government Obstetrics \& Gynecology Hospital in Khammam, Telangana from September 2016 to March 2017. A total of 150 women after delivery were included in the study. A semi structured proforma for sociodemographic details and the Edinburg Postnatal Depression Scale (EPDS) for screening for depressive symptoms were used to collect data from women between 1st and 8th postpartum weeks. Institutes ethics committee approval was taken and consent taken from study participants.

Results: Prevalence of PND was 24\%. PND showed significant association with primiparous women, husband's occupation, unplanned pregnancy and women who preferred male child but gave birth to a female child.

Conclusion: PND screening should be an integral part of postnatal care, so that they are counseled early, thereby preventing future complications.
\end{abstract}

Keywords: Postnatal dépression (PND), Edinburg postnatal depression scale (EPDS), Postpartum.

\section{Introduction}

Depression is a major public health problem that is twice as common in women as men during the childbearing years. Postpartum depression is defined as an episode of nonpsychotic depression according to standardized diagnostic criteria with onset within 1 year of childbirth. ${ }^{1}$

Worldwide about $10 \%$ of pregnant women and $13 \%$ of women who have just given birth, experience a mental disorder primarily depression. In developing countries this is even higher ranging from $15.6 \%$ during pregnancy to $19.8 \%$ after child birth. Some studies show that PND may affect up to $30 \%$ of all women after delivery ${ }^{2}$ and has a significant impact on the mother and long-term consequences on the cognitive and emotional development of children. ${ }^{3}$ The affected mother cannot function properly thereby negatively affecting the growth and development of the child. Sometimes the suffering maybe severe enough to result in suicide. However, maternal psychiatric disorders are treatable. ${ }^{4}$ Therefore early detection reduces a lot of needless suffering.

For women who have experienced PND, up to $50 \%$ will face a reoccurrence during subsequent pregnancies. ${ }^{5}$ PND typically occurs within the first three months after childbirth, lasts a minimum of two weeks, and can cause clinically significant impairment in daily functioning. ${ }^{6}$ According to the World Health Organization (2003), PND symptoms include feelings of anxiety, hopelessness, decreased appetite, inability to concentrate, decreased interest in the baby or life in general, and altered sleep patterns. However, clear guidelines for diagnosing PND is still lacking in the DSM V. ${ }^{7}$

PND describes non-psychotic depressive episodes, with loss of interest, insomnia, and loss of energy experienced by mothers within the period of 4 to 6 weeks after delivery. ${ }^{8}$ PND has multiple risk factors like sociodemographic, economic, psychosocial, obstetric and medical factors. However, inimitable factors such as birth of baby girl, financial insecurity, marital violence, lack of social support have emerged as risk factors for PND in low and medium income countries like India, Pakistan and Turkey. ${ }^{9-11}$

It is considered a serious public health issue because of its devastating effects on mothers, families, and infants or children. ${ }^{12}$ Untreated PND can cause chronic depression and interferes in mother child bonding. Cases of suicide and infanticide have also been rarely reported. ${ }^{13}$

It is estimated that overall 10 to $15 \%$ women experience PND. It ranges from 3.5 to $63.3 \%$ in Asian countries, with Malaysia having the lowest and Pakistan having the highest percentages, respectively. ${ }^{9}{ }^{, 14}$ In view of paucity of research among mothers in local setting and to aid the early diagnosis of PND, this study aimed to elicit prevalence of PND and its associated risk factors among postnatal women approaching Obstetrics \& Gynecology Hospital in Khammam.

\section{Aims and Objectives}

1. To study the prevalence of postnatal depression

2. To study the associated risk factors of postnatal depression

\section{Materials and Methods}

The Study was conducted in Obstetrics \& Gynecology Hospital in Khammam, Telangana. The study period is from September 2016 to March 2017. A total of 150 women after delivery were included in the study through purposive, nonprobability sampling technique. A Cross sectional study. Inclusion Criteria: All the postpartum women who attended the hospitals between 1 st and 8 weeks after delivery and who were willing to participate and had given written consent were included in the study. 
Exclusion Criteria: Postpartum women who had a prior history of any psychiatric illness, major general medical conditions and who were not willing to give written consent were excluded from the study.

Materials: A semi-structured proforma for socio demographic data, Edinburg Postnatal Depression Scale (EPDS) for screening for depressive symptoms and International classification of diseases (ICD-10) for diagnosis were used.

Socio-demographic Profile: Age, religion, education, working status, economic status, husband's occupation and family type; obstetric details: duration of married life, parity, any complications in the last and current pregnancy, pregnancy outcome: gender of the baby, mode and type of delivery. ${ }^{15,16}$

Edinburg Postnatal Depression Scale (EPDS) was used to screen for depressive symptoms. The EPDS contains 10 items, and each item is rated on a four-point scale, giving a maximum scores of 30 . It is a self-report scale based on 1 week recall, designed to screen PND (post-natal depression) in the community. ${ }^{12}$ Each item is rated from 0 to 3, yielding a total score ranging from $0-30$. Seven of its items are reverse scored. A score of 13 or more was considered to be a significant case of postnatal depression, while scores of 10 12 represent borderline and 0-9 represent not depressed. Mothers who scored $>13$ are likely to be suffering from a depressive illness of varying severity.

EPDS scale has been validated to detect antenatal depression, and found to have a sensitivity of $100 \%$ and specificity of $84.9 \%$, at a cut-off score of 13 . Women with EPDS score of $>13$ were further evaluated for depression based on ICD-10 criteria. ${ }^{19}$

The study was approved by the research ethics committee of the institute. Subjects were briefed in detail about the nature and purpose of the study. Confidentiality was assured and informed consent was taken.

\section{Statistical Analysis}

Statistical analysis was done by using Statistical Package for the Social Sciences (SPSS) for Windows, Version 18. Chi-squared test was applied to analyze the data. P-value of less than 0.05 was considered significant.

\section{Results}

A total of 168 women who came for postnatal follow up were approached. However, only 150 were taken up for the study as 8 of them had previous history of psychiatric disorders and 10 of them were not willing to give the written informed consent. Non-participation rate was $10.7 \%$.

Study participants mean age was $23 \pm 2.9$ years (range: 18-33 years). All the postnatal women were living with their partners. Most of them were Hindu $(53 \%)$ by religion and lived in nuclear families $(62.6 \%)$. Literacy rate was $59.4 \%$ and $68.6 \%$ of them were below poverty line. Unemployed $(73.3 \%)$ and prim parous women $(72 \%)$ formed the majority among the study participants. Most of the husbands (61.3\%) were farmers by occupation. Majority (68\%) of them had delivered by cesarean section. Most $(53 \%)$ deliveries were planned pregnancies. Female babies were delivered in 56\% of the cases. Almost every tenth postnatal woman had one or the other complication or medical illness in the last pregnancy. 34\% families have Preference for sex of infant in their last delivery. Of which $22 \%$ families preferred for male child. But in those families $63 \%$ came out to be females $.6 \%$ of infants died after delivery, $4.6 \%$ of women had still births in last pregnancy.

Table 1: Key socio-demographic, obstetric and pregnancy outcome features of the study participants

\begin{tabular}{|l|c|c|}
\hline & Number & \% \\
\hline Age & & \\
\hline$<21$ years & 56 & 37.4 \\
\hline$>21$ years & 94 & 62.6 \\
\hline Education & & \\
\hline Literate & 89 & 59.4 \\
\hline Illiterate & 61 & 40.6 \\
\hline Religion & & \\
\hline Hindu & 80 & 53.4 \\
\hline Muslim & 43 & 28.6 \\
\hline Christian & 27 & 18 \\
\hline Type of family & & \\
\hline Joint & 56 & 37.3 \\
\hline Nuclear & 94 & 62.6 \\
\hline Working status & & \\
\hline Employed & 40 & 26.6 \\
\hline Unemployed & 110 & 73.3 \\
\hline Husbands Occupation & & \\
\hline Farmer & 92 & 61.3 \\
\hline Others & & \\
\hline Socio Economic Status & 58 & 38.6 \\
\hline
\end{tabular}




\begin{tabular}{|l|c|c|}
\hline BPL & 103 & 68.6 \\
\hline APL & 47 & 31.3 \\
\hline Parity & & \\
\hline Multipara & 41 & 27.3 \\
\hline Primi & 109 & 72.7 \\
\hline Pregnancy Planning & 86 & 57.3 \\
\hline Planned & 64 & 42.6 \\
\hline Unplanned & & \\
\hline Mode of Delivery & 48 & 32 \\
\hline Normal & 102 & 68 \\
\hline Cesarean Section & & \\
\hline Type of Delivery & 13 & 8.6 \\
\hline Preterm & 137 & 91.3 \\
\hline Full term & & \\
\hline Gender of the New Born & 84 & 56 \\
\hline Male & 66 & 44 \\
\hline Female & 20 & 13.3 \\
\hline Complications in Pregnancy & 130 & 86.6 \\
\hline Yes & & \\
\hline No & 100 & 66.6 \\
\hline Type of Hospital & 50 & 33.3 \\
\hline Govt & & \\
\hline Private & 51 & 34 \\
\hline Preference for sex of infant in last delivery & 99 & 66 \\
\hline Yes & & \\
\hline No & & 18 \\
\hline Prefered Sex & & 22 \\
\hline F & & 6.6 \\
\hline M & & \\
\hline Number of women whose infant died after delivery & & \\
\hline Number of women who experienced still birth & \\
\hline & & \\
\hline
\end{tabular}

The EPDS score of 36 study participants was $>13$ and the prevalence of PND was $24 \%$. Chi-square test revealed significant $(\mathrm{p}<0.05)$ association with socio demographic (husbands occupation), obstetric (parity, planning of pregnancy) and pregnancy outcome (preference for the sex of infant) variables with PND.
PND showed significant association with primiparous mothers, mothers who had not planned for pregnancy, and mothers who had preference for a male child but delivered a female child instead.

Table 2: Association of socio-demographic, obstetric and pregnancy outcome variables with risk of postnatal depression $(\mathbf{n}=\mathbf{1 5 0})$

\begin{tabular}{|c|c|c|c|c|c|c|}
\hline \multirow[t]{3}{*}{ Study Variable } & \multicolumn{4}{|c|}{ EPDS Score } & \multirow[t]{3}{*}{ Total } & \multirow[t]{2}{*}{ P-value } \\
\hline & \multicolumn{2}{|c|}{$>13$} & \multicolumn{2}{|c|}{$<13$} & & \\
\hline & $\mathrm{N}$ & $\%$ & $\mathrm{~N}$ & $\%$ & & \\
\hline \multicolumn{7}{|l|}{ Age } \\
\hline$<21$ years & 11 & 19.6 & 45 & 80.35 & 56 & \multirow[t]{2}{*}{0.33} \\
\hline$>21$ years & 25 & 26.5 & 69 & 73.40 & 94 & \\
\hline \multicolumn{7}{|l|}{ Education } \\
\hline Literate & 21 & 23.59 & 68 & 76.4 & 89 & \multirow[t]{2}{*}{0.88} \\
\hline Illiterate & 15 & 24.5 & 46 & 75.4 & 61 & \\
\hline \multicolumn{7}{|l|}{ Religion } \\
\hline Hindu & 18 & 22.5 & 62 & 77.5 & 80 & \multirow[t]{3}{*}{0.77} \\
\hline Muslim & 12 & 27.9 & 31 & 72.09 & 43 & \\
\hline Christian & 6 & 22.2 & 21 & 77.7 & 27 & \\
\hline \multicolumn{7}{|l|}{ Type of family } \\
\hline Joint & 14 & 25 & 42 & 75 & 56 & 0.82 \\
\hline
\end{tabular}




\begin{tabular}{|c|c|c|c|c|c|c|}
\hline Nuclear & 22 & 23.4 & 72 & 76.59 & 94 & \\
\hline \multicolumn{7}{|l|}{ Working status } \\
\hline Employed & 7 & 17.5 & 33 & 82.5 & 40 & \multirow[t]{2}{*}{0.26} \\
\hline Unemployed & 29 & 26.3 & 81 & 73.6 & 110 & \\
\hline \multicolumn{7}{|l|}{ Husband's occupation } \\
\hline Farmer & 30 & 32.6 & 62 & 67.39 & 92 & \multirow[t]{2}{*}{$0.001 * *$} \\
\hline Others & 6 & 10.34 & 52 & 89.65 & 58 & \\
\hline \multicolumn{7}{|l|}{ Socio economic satus } \\
\hline Bpl & 27 & 26.21 & 76 & 73.78 & 103 & \multirow[t]{2}{*}{0.34} \\
\hline Apl & 9 & 19.14 & 38 & 80.8 & 47 & \\
\hline \multicolumn{7}{|l|}{ Parity } \\
\hline Multipara & 4 & 9.7 & 37 & 90.24 & 41 & \multirow[t]{2}{*}{$0.015^{* *}$} \\
\hline Primi & 32 & 29.80 & 78 & 71.55 & 109 & \\
\hline \multicolumn{7}{|l|}{ Pregnancy planning } \\
\hline Planned & 13 & 15.1 & 73 & 84.8 & 86 & \multirow[t]{2}{*}{$0.003 * *$} \\
\hline Unplanned & 23 & 35.9 & 41 & 64.06 & 64 & \\
\hline \multicolumn{7}{|l|}{ Mode of delivery } \\
\hline Normal & 15 & 31.25 & 33 & 68.75 & 48 & \multirow[t]{2}{*}{0.15} \\
\hline Cesarean section & 21 & 20.58 & 81 & 79.41 & 102 & \\
\hline \multicolumn{7}{|l|}{ Type of delivery } \\
\hline Preterm & 3 & 23.07 & 10 & 76.9 & 13 & \multirow[t]{2}{*}{0.93} \\
\hline Full term & 33 & 24.08 & 104 & 75.91 & 137 & \\
\hline \multicolumn{7}{|l|}{ Gender of new born } \\
\hline Female & 22 & 26.19 & 62 & 73.8 & 84 & \multirow[t]{2}{*}{0.47} \\
\hline Male & 14 & 21.21 & 52 & 78.78 & 66 & \\
\hline \multicolumn{7}{|l|}{ Complications in pregnancy } \\
\hline Yes & 4 & 20 & 16 & 80 & 20 & \multirow[t]{2}{*}{0.65} \\
\hline No & 32 & 24.61 & 98 & 75.38 & 130 & \\
\hline \multicolumn{7}{|l|}{ Type of hospital } \\
\hline Govt & 25 & 25 & 75 & 75 & 100 & \multirow[t]{2}{*}{0.68} \\
\hline Private & 11 & 22 & 39 & 78 & 50 & \\
\hline \multicolumn{7}{|l|}{ Preference for sex of infant in last delivery } \\
\hline Yes & 8 & 15.68 & 43 & 84.3 & 51 & \multirow[t]{2}{*}{0.08} \\
\hline No & 28 & 28.28 & 71 & 71.71 & 99 & \\
\hline \multicolumn{7}{|l|}{ Preferred sex } \\
\hline Female & 14 & 77.77 & 4 & 22.22 & 18 & \multirow[t]{2}{*}{$0.0002 * *$} \\
\hline Male & 4 & 12.12 & 29 & 87.87 & 33 & \\
\hline $\begin{array}{l}\text { Number of women whose infant died after } \\
\text { delivery }\end{array}$ & 7 & 77.77 & 2 & 22.2 & 9 & \multirow[t]{2}{*}{0.18} \\
\hline Number of women who experienced stillbirth & 7 & 100 & 0 & 0 & 7 & \\
\hline
\end{tabular}

$* *$ Significant, $\mathrm{p}$ value $<0.005$

\section{Discussion}

Pregnancy and childbirth are distinctive life events which are not comparable to natural process of the body since the social and cultural contexts are central to the subjective and collective experiences of women. ${ }^{17}$ Women's age, literacy, social economic status, religion and culture do have a significant influence on pregnancy experiences and her mental health. The present study was an attempt to explore the prevalence and biological risk factors of PND. Prevalence of PND in this study was $24 \%$ and is quite high. Other hospital and community based studies in India have reported lower prevalence of PND ranging from $11 \%$ to $23 \%$. . $^{10,18}$
Current study showed that there is no significant association with the religion and development of postnatal depression which is in contrast to the studies done by some authors, who argued that the individual is bound by the rules of their culture which in turn shape and influence their behavior. ${ }^{19,20}$

Maryam and colleagues in their study conducted in postnatal mother's, concluded that factors such as mother age, birth, gender, and abortion had no significant relationship with PND. ${ }^{21}$ These results are similar to ours, as we did not find any association regarding age, gender of the existing children and history of abortions and miscarriages with PND.

Husband's occupation had significant association with PND in the present study. Most of them were farmers by 
occupation. One conclusion that can be drawn from this finding is that the financial stress found in farmers families may have led to development of PND in postpartum women. Type of family, woman's occupation didn't show any significant association with PND in our study.

Present study showed significant association between PND and planning of pregnancy, women with unplanned pregnancies were depressed compared to the women who had planned for the baby. Similar findings were reported in previous studies, namely unplanned and unwanted pregnancies, operative procedures and difficult labor. ${ }^{22,23}$

The present study and some other Indian studies showed that delivering a female infant and the family's preference for a boy were related to high prevalence of PND. In India preference for the male child is deeply ingrained. Males stay with parents till death and continue their family line, support parents in their old age, conduct funeral rights and inherit ancestral property are some of the cultural norms held in the country. So most people look forward to having a male child and the birth of a baby girl is considered as a family and social stressor in Indian societies. ${ }^{18}$

Present study showed that prim parous women were more depressed than multiparous mothers and the association came to be statistically significant with $p$ value $(<0.05)$, First pregnancies may cause greater psychosocial stress but other biological factors may also play a role. ${ }^{24}$

Canadian prospective cohort study concluded that mode of delivery has no significant impact on PND; which is in accordance with our study findings. ${ }^{25}$ Occurrence of complications or medical illness during pregnancy were not predictors of PND in this study. This could be due to lack of knowledge or cultural norms affecting the reporting of symptoms. ${ }^{26}$

\section{Conclusion}

Prevalence of PND among postnatal women was $24 \%$ in the present study. Unplanned pregnancies, husband's occupation, parity of mother, preference for the sex of infant were associated with high risk of PND. PND screening should be an integral part of postnatal care. Early identification is desirable for better outcome of child and mother health and proper bonding. Educating the gynecologists and patient attendees about the symptoms of PND for early detection and decreasing the disability goes a long way in managing PND. Research regarding the best way to prevent, detect and treat postpartum depression and research which examines the sequel of postpartum depression for the mother and child within diverse ethnic and socioeconomic groups is needed further.

\section{Limitations}

Small sample size is the major limitation of the study and further research needs to be conducted on a larger sample. Results cannot be generalized to the population as the study was hospital based.

\section{Conflicts of Interest: Nil.}

\section{References}

1. Stewart DE, Robertson E, Dennis CL, Grace SL, Wallington T. Postpartum depression: Literature review of risk factors and interventions. Toronto: University Health Network Women's Health Program for Toronto Public Health. 2003 Oct.

2. Evins GG, Theofrastous JP, Galvin SL. Postpartum depression: a comparison of screening and routine clinical evaluation. $\mathrm{Am}$ J Obstet Gynecol. 2000;182(5):1080-1082.

3. Tammentie T, Tarkka MT, Åstedt-Kurki P, Paavilainen E. Sociodemographic factors of families related to postnatal depressive symptoms of mothers. Int J Nurs Pract. 2002;8(5):240-246.

4. World Health Organization. Building back better: sustainable mental health care after emergencies. World Health Organization; 2013 Jul 22.

5. Viguera AC, Nonacs R, Cohen LS, Tondo L, Murray A, Baldessarini RJ. Risk of recurrence of bipolar disorder in pregnant and nonpregnant women after discontinuing lithium maintenance. Am J Psychiatry. 2000;157(2):179-184.

6. Reck C, Struben K, Backenstrass M, Stefenelli U, Reinig K, Fuchs T, Sohn C, Mundt C. Prevalence, onset and comorbidity of postpartum anxiety and depressive disorders. Acta Psychiatrica Scandinavica. 2008;118(6):459-468.

7. Segre LS, Davis WN. Postpartum depression and perinatal mood disorders in the DSM. Postpartum Support International. 2013 Jun.

8. World Health Organization. The World Health Report 2001: Mental health: new understanding, new hope. World Health Organization; 2001.

9. Patel V, Rodrigues M, DeSouza N. Gender, poverty, and postnatal depression: a study of mothers in Goa, India. Am J Psychiatry. 2002;159(1):43-47.

10. Rahman A, Iqbal Z, Harrington R. Life events, social support and depression in childbirth: perspectives from a rural community in the developing world. Psychol Med. 2003;33(07):1161-1167.

11. The Official Website of Mandya District [Internet]. 2014 Available: http://www.mandya.nic.in/. Ac- cessed: $2014 \mathrm{Jul}$ 31.

12. Cox JL, Holden JM, Sagovsky R. Detection of postnatal depression. Development of the 10-item Edinburgh Postnatal Depression Scale. Br J Psychiatry. 1987;150(6):782-786.

13. Pearlstein T, Howard M, Salisbury A, Zlotnick C. Postpartum depression. American journal of obstetrics and gynecology. 2009;200(4):357-364.

14. Teissèdre $\mathrm{F}, \mathrm{Chabrol} \mathrm{H}$. Detecting women at risk for postnatal depression using the Edinburgh Postnatal Depression Scale at 2 to 3 days postpartum. Can J Psychiatry. 2004;49(1):51-54.

15. Park K. Medicine and Social Sciences. Park's Textbook of Preventive Medicine. 22nd ed. Jabalpur: M/s Banarsidas Bhanot Publishers, 2013: 620-53.

16. Wainstock T, Anteby EY, Glasser S, Lerner-Geva L, ShohamVardi I. Exposure to life-threatening stressful situations and the risk of preterm birth and low birth weight. Int J Gynecol Obstet. 2014;125(1):28-32.

17. Sookhoo D, Race ethnicity, culture and childbirth. In: Squire C editor. The Social Context of Birth. Oxon, England: Redcliffe publishing Ltd; 2009. p.85

18. Avinash K. Postpartum depression: prevalence and associated factors among women in India. J Women's Health, Issues \& Care. 2012 Sep 17.

19. Lazarus RS, Folkman S. Coping and adaptation. The Handbook of Behavioral Medicine. 1984:282-325. 
20. Cox JL. Clinical and research aspects of post-natal depression. J Psychosom Obstet Gynecol. 1983;2(1):46-53.

21. Mazaheri MA, Rabiei L, Masoudi R, Hamidizadeh S, Nooshabadi MR, Najimi A. Understanding the factors affecting the postpartum depression in the mothers of Isfahan city. J Edu Health Promot. 2014;3.

22. Ghubash R, Abou-Saleh MT. Postpartum psychiatric illness in Arab culture: prevalence and psychosocial correlates. The British Journal of Psychiatry. 1997;171(1):65-68.

23. Golbasi Z, Kelleci M, Kisacik G, Cetin A. Prevalence and correlates of depression in pregnancy among Turkish women. Maternal Child health J. 2010;14(4):485.
24. Dowlatshahi D, Paykel ES. Life events and social stress in puerperal psychoses: absence of effect. Psychological Medicine. 1990;20(3):655-662.

25. Sword W, Kurtz Landy C, Thabane L, Watt S, Krueger P, Farine D, Foster G. Is mode of delivery associated with postpartum depression at 6 weeks: a prospective cohort study. BJOG: Int J Obstet Gynaecol. 2011;118(8):966-977.

26. Mancini F, Carlson C, Albers L. Use of the Postpartum Depression Screening Scale in a collaborative obstetric practice. J Midwifery Women's Health. 2007;52(5):429-434. 